\title{
Long-term Functional Difference between the First and Second Knees in Simultaneous Bilateral Total Knee Arthroplasty
}

\author{
Omer Ersen, Ahmet Burak Bilekli, Serhat Uzun, Yusuf Erdem, Dogan Bek and Cemil Yildiz \\ Department of Orthopedics, Gulhane Education and Research Hospital, Ankara, Turkey
}

\begin{abstract}
Objective: To compare the long-term functional results of the first and second knees in simultaneous bilateral total knee arthroplasty.

Study Design: Descriptive study.

Place and Duration of Study: Gulhane Education and Research Hospital, Ankara, Turkey from January 2003 to December 2010.

Methodology: A total of 47 patients with at least 10 years of follow-up after simultaneous bilateral total knee arthroplasty were included in the study. The range of motion, forgotten joint score (FJS), Oxford knee score (OKS), and Western Ontario McMaster university osteoarthritis index (WOMAC) were compared between the first and the second knees. The Dependent ttest and the Wilcoxon Sign test were used to determine the significance. Whether there was a statistically significant correlation, so Spearman's correlation test and Bonferroni correction were used.

Results: WOMAC total scores both knees were $13(p=0.755)$. The average OKS of the first operated knees was $40.53 \pm 4.44$, while it was $40.28 \pm 4.59$ in the second knees $(p=0.239)$. The FJS of the first and second operated knees were $69.36 \pm 21.97$ and $69.02 \pm 21.89$, respectively $(p=0.321)$. As the age increased, the ROM was decreased. As the patient age increased, WOMAC pain scores were found to decrease.

Conclusion: The functional scores of the first and the second operated knees in SBTKA were similar in the long term. Although no correlation was found between age and the functional scores, these results complied with the previous information about the effect of age on TKA results.
\end{abstract}

Key Words: Simultaneous total knee arthroplasty, Bilateral, Clinical outcome, Osteoarthritis.

How to cite this article: Ersen O, Bilekli AB, Uzun S, Erdem Y, Bek D, Yildiz C. Long-term Functional Difference between the First and Second Knees in Simultaneous Bilateral Total Knee Arthroplasty. J Coll Physicians Surg Pak 2021; 31(11):1320-1324.

\section{INTRODUCTION}

Bilateral knee osteoarthritis usually requires bilateral total knee arthroplasty. ${ }^{1-4}$ Bilateral surgery can be done simultaneously or in staged procedures. The advantages of simultaneous bilateral total knee arthroplasty (SBTKA) are less anesthesia time, decreased length of hospitalisation, and decreased rehabilitation time. ${ }^{1-5}$ AlthoughSBTKA wasfound as safe as a staged procedure, care should be taken especially for high-risk patients. ${ }^{1}$ The desired goal of total knee arthroplasty (TKA) is to obtain a painfree functional joint. Various outcome scores were used to evaluate the patient's function after TKA. ${ }^{6,7}$

Correspondence to: Dr. Omer Ersen, Department of Orthopedics, Gulhane Education and Research Hospital,

Ankara, Turkey

E-mail: merschenn@yahoo.com

Received: November 20, 2020; Revised: August 06, 2021;

Accepted: September 23, 2021

DOI: https://doi.org/10.29271/jcpsp.2021.11.1320
Surgeons usually start the simultaneous procedure with the more painful and affected knee. It can be expected that preoperative worse knee causes a worse outcome, but the knee awareness and function found similar in short- or mid-term between the knees. ${ }^{5,6}$ In contrast, a surgeon can learn the anatomy of the patient in the first knee; and the second knee surgery becomeseasier.

The main purpose of this study was to compare long-term knee awareness and functional outcomes between the first and second knees during SBTKA with at least ten years of follow-up.

\section{METHODOLOGY}

Patients, who were treated by SBTKA in Department of Orthopedics, Gulhane Faculty of Medicine, at least 10 years ago (2003-2010), were included in this retrospective study. Patients who had another major orthopedic surgery or revision total knee arthroplasty, patients who had early major complications due to SBTKA surgery, and patients with dementia, were excluded from the study. Forty-seven patients ( 6 males, 41 females) enrolled in this study. This study was approved by the local Ethics Committee (15.05.2020, No. 2020-189). 
Surgical procedures were the same; and more symptomatic knee was operated on first for all patients. A midline longitudinal skin incision, medial parapatellar arthrotomy, and combined spinal/epidural anesthesia were used. Demographic data of the patients were documented for all patients. Clinical evaluation was made by a range of motion (ROM), forgotten joint score (FJS), Oxford knee score (OKS), and Western Ontario McMaster university osteoarthritis index (WOMAC) for each knee of the patients.

Analysis of the data was done in IBM SPSSStatistics version 17.0 (IBM Corporation, Armonk, NY, USA) package programme. Whether the distributions of continuous variables were normal or not being determined by Shapiro-Wilk test. Categorical data were expressed as numbers ( $n$ ) and percentage(\%), whilequantitative data were given as mean \pm S.D, and median (IQR: $25^{\text {th }}$ percentile- $75^{\text {th }}$ percentile). Whether there was a statistically significant difference between the 1st knees and 2nd knees in the groups in terms of ROM, FJS, and OKS measurements were evaluated with the Dependent t-test, and the significance of the differences in terms of WOMAC scores was evaluated with the Wilcoxon Sign test. While the significance of the differences between the groups in terms of ROM, FJS, and OKS measurements was evaluated with Student's t-test, the significance of the differences in terms of WOMAC scores was examined with the Mann-Whitney U-test. The patients were divided into two groups as over 65 years old, and under 65 years, according to their age at the time of surgery. Whether there was a statistically significant correlation between the age, BMI, and functional scores, Spearman's correlation test was used. Unless otherwise stated, results for $p<0.05$ were considered statistically significant. However, Bonferroni correction was made to control type lerror in all possible multiple comparisons.

\section{RESULTS}

Average age at the time of SBTKA surgery was $64.55 \pm 5.52$; and 41 of the patients were females (87.2\%). The average weight was $81.3 \pm 11.61 \mathrm{Kgs}$, the average height was $1.62 \pm 0.071$ meters, and average BMI was $31.08 \pm 4.59 \mathrm{Kg} / \mathrm{m}^{2}$. The average follow-up period was 12 (11-17) years.

The first operated side was right, in 25 patients; and it was left in 22 patients. Only 6 patients $(12.8 \%)$ remembered which knee was operated on first. The mean ROM was statistically significantly higher in the second operated knee than the first operated knee $(p=0.001)$. There was no statistically significant difference between the knees in terms of WOMAC scores ( $p$ $>0.05$ ). Moreover, no statistically significant difference was found between the knees in terms of FJS and OKS averages $(p=$ 0.321 and $p=0.239$, respectively, Table I).

In patients who were operated before the age of 65 years, the mean ROM was higher in the second operated knee $(p=0.005)$. But there was no statistical difference compared to the Bonferroni Correction ( $p=0.045$ ). The mean ROM in both knees was statistically lower in patients aged 65 and over, compared to patients under 65 years ( $p=0.005$ and $p=0.006$, respectively). Age did not have a statistically significant modifying effect on the mean ROM difference between the knees $(p=0.700)$.

There were no statistical differences between the knees according to the Bonferroni correction in terms of WOMAC scores ( $p>0.025)$. Age affected the change in the WOMAC pain level in the second operated knees compared to the first ones. WOMAC pain level increased in patients under 65 years of age, while WOMAC pain level decreased in patients 65 years and older $(p=0.001)$. However, age did nothavea statistically significant modifying effect on other WOMAC scores ( $p>0.05)$, or mean FJS and OKS differences between the knees ( $p=0.562$ and $p=0.930$, respectively, Table II).

No statistically significant difference was found between the patients with $\mathrm{BMI}<30$; and the patients with $\mathrm{BMI} \geq 30$, in terms of ROM averages in both knees $(p=0.494$ and $p=0.287)$. When ROM, WOMAC scores, FJS, and OKS of these groups were compared, and the Bonferroni correction applied, no statistical difference was found. BMI had no statistically significant modifying effect on the mean ROM, WOMAC score, FJS, and OKS differences in the second knees, compared to the first knees ( $p=$ $0.393, p>0.05, p=0.437$, and $p=0.766$, respectively, Table II).

As the age at the surgery time increased, the ROM in the first and the second operated knees decreased statistically ( $r=-0.455$ / $p=0.001$ and $r=-0.405 / p=0.005)$. In both knees, there was no statistically significant correlation between age and functional scores, according to Bonferroni correction ( $p>0.025$ ). Similarly, there was no statistical correlation between BMI and the functional scores, according to Bonferroni correction ( $p$ $>0.025$ ).

As the age at the time of the surgery increased, the WOMAC pain level in the second knee decreased statistically significantly more than the first operated knee $(r=-0.360$ and $p=0.013)$. However, there was no statistically significant correlation between the age and BMI and the measurement differences in the second operated knees compared to the first operated knees ( $p>0.05$, Table III).

\section{DISCUSSION}

In the present study, the authors compared the functional outcomes of the knees, according to the operation order in SBTKA patients with at least 10 years of follow-up. WOMAC total scores, OKS, and FJS were similar between the knees. The WOMAC pain score was higher in younger patients.

Table I: Clinical evaluation of the first and second operated knees.

\begin{tabular}{|l|l|l|l|}
\hline & 1st knee & 2nd knee & p \\
\hline ROM & $94.17 \pm 8.12$ & $96.68 \pm 8.97$ & $0.001 \dagger$ \\
\hline WOMAC & $1(0-3)$ & $2(0-3)$ & $0.564 \ddagger$ \\
\hline Pain & $0(0-2)$ & $0(0-2)$ & $>0.999 \ddagger$ \\
\hline Stiffness & $11(7-15)$ & $12(7-16)$ & $0.567 \ddagger$ \\
\hline Function & $13(9-20)$ & $13(9-20)$ & $0.755 \ddagger$ \\
\hline Total & $69.36 \pm 21.97$ & $69.02 \pm 21.89$ & $0.321 \dagger$ \\
\hline FJS & $40.53 \pm 4.44$ & $40.28 \pm 4.59$ & $0.239 \dagger$ \\
\hline OKS & † Dependent t-test, $\neq$ Wilcoxon sign test, significance level $p<0,05$. \\
\hline
\end{tabular}


Table II: Clinical evaluation of the first and the second knees according to the age and BMI.

\begin{tabular}{|c|c|c|c|c|c|c|c|c|c|c|c|c|c|c|c|c|c|c|c|c|c|}
\hline & \multicolumn{21}{|c|}{ BMI } \\
\hline & \multicolumn{3}{|c|}{ ROM } & \multicolumn{3}{|c|}{ WOMAC Pain } & \multicolumn{3}{|c|}{ WOMAC Stiffness } & \multicolumn{3}{|c|}{ WOMAC Function } & \multicolumn{3}{|c|}{ WOMAC Total } & \multicolumn{3}{|c|}{ FJS } & \multicolumn{3}{|c|}{ OKS } \\
\hline & BMI $<30$ & BMI >30 & $\mathbf{p}^{2}$ & BMI $<30$ & BMI >30 & $\mathbf{p}^{2}$ & BMI $<30$ & BMI >30 & $p^{2}$ & $\begin{array}{l}\text { BMI } \\
<30\end{array}$ & BMI >30 & $\mathbf{p}^{2}$ & BMI $<30$ & BMI >30 & $\mathbf{p}^{2}$ & BMI $<30$ & BMI > 30 & $\mathbf{p}^{2}$ & BMI $<30$ & BMI >30 & $p^{2}$ \\
\hline 1st knee & $\begin{array}{l}95.05 \\
\pm 8.24 \\
\end{array}$ & $\begin{array}{l}93.40 \\
\pm 8.10\end{array}$ & $0.494 \mathrm{tt}$ & $\begin{array}{c}1 \\
(1-2)\end{array}$ & $\begin{array}{c}2 \\
(0-4)\end{array}$ & $0.535 \#$ & $\begin{array}{c}0.5 \\
(0-2) \\
(0)\end{array}$ & $\begin{array}{c}0 \\
(0-2) \\
\end{array}$ & 0.711 \# & $\begin{array}{c}10.5 \\
(8.75-15.25)\end{array}$ & $\begin{array}{c}11 \\
(7-16)\end{array}$ & 0.856 抹 & $\begin{array}{c}13 \\
(10-17)\end{array}$ & $\begin{array}{c}15 \\
(8-22)\end{array}$ & 0.949 \# & $\begin{array}{c}68.14 \\
\pm 20.59\end{array}$ & $\begin{array}{c}70.44 \\
\pm 23.48\end{array}$ & $0.724+t$ & $40.77 \pm 4.59$ & $40.32 \pm 4.38$ & $0.731 \mathrm{tt}$ \\
\hline 2nd knee & $\begin{array}{l}98.18 \\
\pm 8.58\end{array}$ & $\begin{array}{l}95.36 \\
\pm 9.26\end{array}$ & $0.287 \mathrm{tt}$ & $\begin{array}{c}1 \\
(0.75-2)\end{array}$ & $\begin{array}{c}2 \\
(0-3.5)\end{array}$ & $0.577 \#$ & $\begin{array}{c}0.5 \\
(0-2)\end{array}$ & $\begin{array}{c}0 \\
(0-2)\end{array}$ & $0.926 \neq$ & $\begin{array}{c}11 \\
(8-15.25)\end{array}$ & $\begin{array}{c}12 \\
(6-16)\end{array}$ & 0.789 㧊 & $\begin{array}{c}12.5 \\
(10-19)\end{array}$ & $\begin{array}{c}15 \\
(7.5-22)\end{array}$ & 0.881 \# & $\begin{array}{c}68.00 \\
\pm 20.92\end{array}$ & $\begin{array}{c}69.92 \\
\pm 23.11\end{array}$ & $0.768 \mathrm{tt}$ & $40.41 \pm 4.79$ & $40.16 \pm 4.51$ & $0.855 \mathrm{tt}$ \\
\hline$p^{1}$ & $0.005 t$ & $0.047 \dagger$ & & $0.796 \neq$ & $0.564 \ddagger$ & & $0.317 \ddagger$ & $0.317 \neq$ & & $0.291 \neq$ & $0.867 \ddagger$ & & $0.384 \ddagger$ & $0.687 \ddagger$ & & $0.795 t$ & $0.261 \dagger$ & & $0.304 \dagger$ & $0.557 \dagger$ & \\
\hline \multirow[t]{3}{*}{ Difference } & $\begin{array}{c}3.14 \\
\pm 4.64\end{array}$ & $\begin{array}{c}1.96 \\
\pm 4.69\end{array}$ & $0.393 \mathrm{tt}$ & $\begin{array}{c}0 \\
(-1-0.25)\end{array}$ & $\begin{array}{c}0 \\
(-1-0)\end{array}$ & $0.991 \#$ & $\begin{array}{c}0 \\
(0-0)\end{array}$ & $\begin{array}{c}0 \\
(0-0)\end{array}$ & 0.161 抹 & $\begin{array}{c}0 \\
(-1-1)\end{array}$ & $\begin{array}{c}0 \\
(-1-1)\end{array}$ & 0.416 扭 & $\begin{array}{c}0 \\
(-1-2)\end{array}$ & $\begin{array}{c}0 \\
(-1-1)\end{array}$ & $0.472 \#$ & \begin{tabular}{|c}
0.0 \\
$(-1.25-$ \\
$1.0)$
\end{tabular} & $\begin{array}{c}0.0 \\
(-2.0-1.0)\end{array}$ & 0.437 㧊 & $\begin{array}{c}-0.5 \\
(-1.0-1.0)\end{array}$ & $\begin{array}{c}0.0 \\
(-1.0-1.0)\end{array}$ & $0.766 \neq$ \\
\hline & \multicolumn{21}{|c|}{ Age } \\
\hline & $<65$ & $\geq 65$ & $p^{2}$ & $<65$ & $\geq 65$ & $p^{2}$ & $<65$ & $\geq 65$ & $p^{2}$ & $<65$ & $\geq 65$ & $p^{2}$ & $<65$ & $\geq 65$ & $p^{2}$ & $<65$ & $\geq 65$ & $p^{2}$ & $<65$ & $\geq 65$ & $p^{2}$ \\
\hline 1st knee & $\begin{array}{l}97.20 \\
\pm 7.53\end{array}$ & $\begin{array}{l}90.73 \\
\pm 7.50\end{array}$ & $0.005 \mathrm{tt}$ & $\begin{array}{c}1 \\
(0-2.5)\end{array}$ & $\begin{array}{c}1.5 \\
(1-3.25)\end{array}$ & 0.332 㧊 & $\begin{array}{c}1 \\
(0-2)\end{array}$ & $\begin{array}{c}0 \\
(0-2)\end{array}$ & $0.644 \neq \neq$ & $\begin{array}{c}10 \\
(6-14)\end{array}$ & $\begin{array}{c}11.5 \\
(8.75-19.75)\end{array}$ & $0.189 \neq \ddagger$ & $\begin{array}{c}13 \\
(8-17.5)\end{array}$ & $14(10-26)$ & $0.236 \#$ & $\begin{array}{c}71.64 \\
\pm 23.23\end{array}$ & $\begin{array}{c}66.77 \\
\pm 20.67\end{array}$ & $0.455 \mathrm{tt}$ & $40.92 \pm 4.10$ & $40.09 \pm 4.85$ & $0.529+t$ \\
\hline 2nd knee & $\begin{array}{r}99.96 \\
\pm 8.75 \\
\end{array}$ & $\begin{array}{l}92.95 \\
\pm 7.83 \\
\end{array}$ & $0.006+t$ & $\begin{array}{c}2 \\
(0-2.5)\end{array}$ & $\begin{array}{c}1 \\
(0-3.25) \\
\end{array}$ & $0.878 \#$ & $\begin{array}{c}1 \\
(0-2) \\
\end{array}$ & $\begin{array}{c}0 \\
(0-3) \\
\end{array}$ & $0.853 \neq \neq$ & $\begin{array}{c}9 \\
(6-15) \\
\end{array}$ & $\begin{array}{c}13.5 \\
(8-20.5) \\
\end{array}$ & $0.113 \neq$ & \begin{tabular}{|c|}
12 \\
$(8.5-17.5)$ \\
\end{tabular} & $\begin{array}{c}14 \\
(9.5-25.25)\end{array}$ & $0.353 \#$ & $\begin{array}{r}71.56 \\
\pm 22.79 \\
\end{array}$ & $\begin{array}{r}66.14 \\
\pm 20.98 \\
\end{array}$ & $0.403+t$ & $40.72 \pm 4.17$ & $39.77 \pm 5.08$ & $0.486 \mathrm{tt}$ \\
\hline$p^{1}$ & $0.005 t$ & $0.045 t$ & & $0.058 \neq$ & $0.029 \neq$ & & $0.564 \neq$ & $0.655 \neq$ & & $0.695 \neq$ & $0.659 \ddagger$ & & $0.248 \neq$ & $0.460 \ddagger$ & & $0.867 \dagger$ & $0.208 \dagger$ & & $0.422 \dagger$ & $0.398+$ & \\
\hline Difference & $\begin{array}{c}2.76 \\
\pm 4.50\end{array}$ & $\begin{array}{c}2.23 \\
\pm 4.91\end{array}$ & $0.700+t$ & $\begin{array}{c}0 \\
(0-1)\end{array}$ & $\left(\begin{array}{c}-1 \\
(-1-0)\end{array}\right.$ & $0.001 \neq$ & $\begin{array}{c}0 \\
(0-0)\end{array}$ & $\begin{array}{c}0 \\
(0-0)\end{array}$ & $0.483 \neq \neq$ & $\begin{array}{c}0 \\
(-1-1)\end{array}$ & $\begin{array}{c}0 \\
(-1-1)\end{array}$ & 0.947 \# & $\begin{array}{c}0 \\
(-1-2)\end{array}$ & $\begin{array}{l}-0.5 \\
(-1-1)\end{array}$ & $0.231 \neq$ & $\begin{array}{c}0.0 \\
(-2.0- \\
1.0)\end{array}$ & $\begin{array}{c}0.0 \\
(-2.0- \\
0.25)\end{array}$ & $0.562 \neq \#$ & $\begin{array}{c}-1.0 \\
(-1.0-1.0)\end{array}$ & $\begin{array}{c}0.0 \\
(-2.0-1.0)\end{array}$ & $0.930 \neq$ \\
\hline
\end{tabular}

Table III: Correlation coefficients and significance levels between age and body mass index and clinical measurements of the first and the second knees.

\begin{tabular}{|c|c|c|c|c|}
\hline & \multicolumn{2}{|l|}{ Age } & \multicolumn{2}{|c|}{ Body mass index } \\
\hline & $r$ & $p \dagger$ & $r$ & $\mathrm{p} \dagger$ \\
\hline \multicolumn{5}{|l|}{ 1st knee } \\
\hline ROM & -0.455 & 0.001 & -0.054 & 0.717 \\
\hline WOMAC pain & 0.287 & 0.050 & -0.100 & 0.506 \\
\hline $\begin{array}{l}\text { WOMAC } \\
\text { stiffness }\end{array}$ & -0.065 & 0.663 & 0.071 & 0.633 \\
\hline $\begin{array}{l}\text { WOMAC } \\
\text { function }\end{array}$ & 0.277 & 0.060 & -0.049 & 0.745 \\
\hline WOMAC total & 0.265 & 0.072 & -0.039 & 0.796 \\
\hline FJS & -0.164 & 0.269 & 0.138 & 0.356 \\
\hline OKS & -0.196 & 0.186 & 0.027 & 0.859 \\
\hline \multicolumn{5}{|l|}{ 2nd knee } \\
\hline ROM & -0.405 & 0.005 & -0.148 & 0.320 \\
\hline WOMAC pain & 0.192 & 0.196 & -0.084 & 0.576 \\
\hline $\begin{array}{l}\text { WOMAC } \\
\text { stiffness }\end{array}$ & -0.039 & 0.796 & 0.077 & 0.606 \\
\hline $\begin{array}{l}\text { WOMAC } \\
\text { function }\end{array}$ & 0.307 & 0.036 & -0.086 & 0.563 \\
\hline WOMAC total & 0.264 & 0.073 & -0.098 & 0.513 \\
\hline FJS & -0.157 & 0.292 & 0.134 & 0.368 \\
\hline OKS & -0.226 & 0.126 & 0.071 & 0.637 \\
\hline \multicolumn{5}{|c|}{ 2nd knee - 1st knee } \\
\hline ROM & -0.030 & 0.842 & -0.077 & 0.606 \\
\hline WOMAC pain & -0.360 & 0.013 & 0.011 & 0.943 \\
\hline $\begin{array}{l}\text { WOMAC } \\
\text { stiffness }\end{array}$ & 0.051 & 0.731 & -0.057 & 0.703 \\
\hline $\begin{array}{l}\text { WOMAC } \\
\text { function }\end{array}$ & 0.000 & 0.999 & -0.265 & 0.072 \\
\hline WOMAC total & -0.120 & 0.422 & -0.173 & 0.244 \\
\hline FJS & 0.005 & 0.972 & 0.073 & 0.628 \\
\hline OKS & -0.085 & 0.570 & 0.167 & 0.262 \\
\hline \multicolumn{5}{|c|}{$\begin{array}{l}\text { r: Correlation coefficient, + Spearman's rank correlation test, According to } \\
\text { the Bonferroni Correction in the correlation analysis in terms of the } \\
\text { measurements of the } 1 \text { st and } 2 \text { nd knees, the results for } p<0.025 \text { were } \\
\text { considered statistically significant. In the correlation analysis performed } \\
\text { for the change of measurements between the knees, the results for } p \\
<0.05 \text { were considered. Statistically significant. }\end{array}$} \\
\hline
\end{tabular}

The average ROM of the first operated knees was statistically higher than the second, but the difference was only $2.5,^{\circ}$ and it was not possible to claim that this represents a functional difference. The ROM of the knees was lower in the elderly patients, but no correlation was found between the functional scores and the age. The BMI of the patients at the final visit was not related to the functional outcomes.

Most of the previous studies focused on the complications, infection rates as well as functional scores. These studies compared simultaneous and staged procedures. ${ }^{1,2,8-12}$ Shorter hospital stay, shorter rehabilitation period, and lower hospital costs are the advantages of SBTKA. Multiple studies demonstrated similar complication risks when compared with the staged bilateral TKA. ${ }^{2,8,11,13}$ In this study, the authors aimed to compare the functional results of the first operated knee and the second one as distinct from the interest of the previous studies. The WOMAC total, OKS, and FJS were found similar between the knees in SBTKA patients.

FJS is a patient-reported outcome measure that objectively differentiates problems due to artificial joint or general health problems. ${ }^{5,14-17}$ Latifi et al. compared the knee awareness of SBTKA and unilateral TKA patients by FJS; and Nielsen et al. compared the best knees and the worst knees of 99 patients. Both studies found no difference. ${ }^{4,6}$ In the present study, knee awareness of the first and second operated knees in SBTKA patients was compared with at least 10 years of follow-up and the scores of the knees were similar.

Surgeons usually start the SBTKA with the more symptomatic knee to allow staged procedures, if needed. When the effect of preoperative functional status on postoperative functional results considered, different functional results of the knees can be expected. Furthermore, the operation of the first knee in SBTKA gives information about the anatomy of the patient and can ease the operation of the contralateral side. ${ }^{2,3,18}$. Seo et al. hypothesised that the operations of the knees in SBTKA are disparate situations and would have different results in 420 patients; but found no difference between the knees in short term. ${ }^{2}$ In the present study, the ROM of the second knees was higher. But this difference did not affect the OKS and WOMAC total scores of the patients.

The most effective symptom that makes patients willing to undergo TKA is pain. Younger patients desire more function which brings along much residual pain; while elderly patients desire pain relief and accept less function. ${ }^{19,20}$ In this study, the outcomes of SBTKA patients over and under 65 years of age were also compared. WOMAC-pain scores of the patients under 65 years were found higher. Moreover, as the age 
increased, the ROM was decreased. The difference of the average ROM was approximately $7^{\circ}$ between the patients who were operated on, over 65 years of age and under 65 . Although no correlation was found between age and the functional scores, these results complied with the previous information about the effect of age on TKA results.

This study has some limitations. First, the retrospective design of the study prevents assessing the functional status of the patients in the preoperative and early postoperative periods. Second, the small sample size, which was due to the long follow-up period, prevents making a stronger opinion on this topic.

\section{CONCLUSION}

The functional scores of the first and the second operated knees in SBTKA were similar in the long term. Although the average ROM of the second knees was $2.5^{\circ}$ higher, this difference has no clinical significance. The ROM was lower in elder patients and the WOMAC-pain scores were higher in younger patients. The functional outcomes of more painful knees were similar to the others.

\section{ETHICAL APPROVAL:}

Ethics Committee approval for the study was received from Gulhane Education and Research Hospital Local Ethics Committee. (2020-189, dated: 15/05/2020)

\section{PATIENTS' CONSENT:}

The necessary consent forms were obtained from all the patients for the study.

\section{CONFLICT OF INTEREST:}

The authors declared no conflict of interest.

\section{AUTHORS' CONTRIBUTION:}

OE: Study design, interpretation of the data, writing the manuscript, drafting the work.

ABB: Analysis of the data, statistical supervision.

$\mathrm{SU}$ : Acquisition, analysis, interpretation of the data, and literature review.

YE: Designing of the work; interpretation of data for the work.

DB, CY: Critical review as senior surgeon of the patients, study design.

\section{REFERENCES}

1. Seol JH, Seon JK, Song EK. Comparison of postoperative complications and clinical outcomes between simultaneous and staged bilateral total knee arthroplasty. J Orthop Sci 2016; 21(6):766-9. doi: 10.1016/j.jos.2016.07.023.

2. Seo JG, Lee BH, Moon YW, Chang MJ, Park SH. Disparate postoperative results in the first and second knees on simultaneous bilateral total knee arthroplasty. J Arthroplasty 2014; 29(12):2331-6. doi: 10.1016/j.arth.2014.07.025.

3. Hersekli MA, Akpinar S, Ozalay M, Ozkoç G, Uysal M, Cesur $\mathrm{N}$, et al. A comparison between single- and two-staged bilat- eral total knee arthroplasty operations in terms of the amount of blood loss and transfusion, perioperative complications, hospital stay, and cost-effectiveness. Acta Orthop Traumatol Turc 2004; 38(4):241-6.

4. Latifi R, Thomsen MG, Kallemose T, Husted H, Troelsen A. Knee awareness and functionality after simultaneous bilateral vs unilateral total knee arthroplasty. World J Orthop 2016; 7(3):195-201.

5. Patil N, Wakankar H. Morbidity and mortality of simultaneous bilateral total knee arthroplasty. Orthopedics 2008; 31(8):780-791. doi: 10.3928/01477447-20080801-23.

6. Nielsen KA, Thomsen MG, Latifi R, Kallemose T, Husted $H$, Troelsen A. Does post-operative knee awareness differ between knees in bilateral simultaneous total knee arthroplasty? Predictors of high or low knee awareness. Knee Surg Sports Traumatol Arthrosc 2016; 24(10):3352-8. doi: 10.1007/s00167-016-4013-5.

7. Bourne RB, Chesworth BM, Davis AM, Mahomed NN, Charron KD. Patient satisfaction after total knee arthroplasty: who is satisfied and who is not? Clin Orthop Relat Res 2010; 468(1):57-63. doi: 10.1007/s11999-009-1119-9.

8. Sheth DS, Cafri G, Paxton EW, Namba RS. Bilateral simultaneous vs. staged total knee arthroplasty: A comparison of complications and mortality. J Arthroplasty 2016; 31 (9 Suppl):212-6. doi: 10.1016/j.arth.2016.03.018.

9. Liu L, Liu H, Zhang H, Song J, Zhang L. Bilateral total knee arthroplasty: Simultaneous or staged? A systematic review and meta-analysis. Medicine (Baltimore) 2019; 98(22): e15931. doi: 10.1097/MD.0000000000015931.

10. Fick D, Crane T, Shakespeare D. A comparison of bilateral vs. unilateral total knee arthroplasty mobilised using a flexion regime. Knee. 2002; 9(4):285-9. doi: 10.1016/ s0968-0160(02)00038-8.

11. Ritter MA, Harty LD, Davis KE, Meding JB, Berend M. Simultaneous bilateral, staged bilateral, and unilateral total knee arthroplasty. A survival analysis. J Bone Joint Surg Am 2003; 85(8):1532-7. doi: 10.2106/00004623-200308000-00015.

12. Reuben JD, Meyers SJ, Cox DD, Elliott M, Watson M, Shim $\mathrm{SD}$. Cost comparison between bilateral simultaneous, staged, and unilateral total joint arthroplasty. J Arthroplasty 1998; 13(2):172-9. doi: 10.1016/s0883-5403(98) 90095-x.

13. Horne G, Devane P, Adams K. Complications and outcomes of single-stage bilateral total knee arthroplasty. ANZ J Surg 2005; 75(9):734-738. doi: 10.1111/j.1445-2197. 2005. 03513.x.

14. Thienpont E, Opsomer G, Koninckx A, Houssiau F. Joint awareness in different types of knee arthroplasty evaluated with the forgotten joint score. J Arthroplasty 2014; 29(1):48-51. doi: 10.1016/j.arth.2013.04.024.

15. Giesinger K, Hamilton DF, Jost B, Holzner B, Giesinger JM. Comparative responsiveness of outcome measures for total knee arthroplasty. Osteoarthritis Cartilage 2014; 22(2):1849. doi: 10.1016/j.joca.2013.11.001.

16. Behrend H, Giesinger K, Giesinger JM, Kuster MS. The "forgotten joint" as the ultimate goal in joint arthroplasty: Validation of a new patient-reported outcome measure. J Arthroplasty. 2012; 27(3):430-436. doi: 10.1016/j.arth. 
2011.06 .035$.

17. Escobar A, Quintana JM, Bilbao A, Azkárate J, Güenaga JI, Arenaza JC, et al. Effect of patient characteristics on reported outcomes after total knee replacement. Rheumatol (Oxford) 2007; 46(1):112-9. doi: 10.1093/rheumatology/kel184.

18. Capeci CM, Brown EC, Scuderi GR, Scott WN. Component asymmetry in simultaneous bilateral total knee arthroplasty. J Arthroplasty 2006; 21(5):749-753. doi: 10.1016/ j.arth.2005.09.010.

19. Niki Y, Nagura T, Kobayashi S, Udagawa K, Harato K. Who will benefit from kinematically aligned total knee arthroplasty? Perspectives on patient-reported outcome measures. J Arthroplasty 2020; 35(2):438-442. doi: 10. 1016/j.arth.2019.09.035.

20. Parvizi J, Nunley RM, Berend KR, Lombardi AV Jr, Ruh EL, Clohisy JC, et al. High level of residual symptoms in young patients after total knee arthroplasty. Clin Orthop Relat Res 2014; 472(1):133-7. doi: 10.1007/s11999-013-3229-7. 